\title{
Numerical Models to Predict the Performance of Tidal Stream Turbines Working under Off-Design Conditions
}

\author{
S. Ordonez-Sanchez ${ }^{1}$, R. Ellis², K. E. Porter ${ }^{1}$, M. Allmark², T. O'Doherty ${ }^{2}$, A. Mason-Jones ${ }^{2}$, C. \\ Johnstone $^{1}$ \\ ${ }^{1}$ Energy Systems Research Unit, University of Strathclyde, Glasgow G1 1 XJ, Scotland, UK \\ ${ }^{2}$ School of Engineering, Cardiff University, Queens Buildings, The Parade, Cardiff CF24 3AA, Wales, UK \\ Stephanie Ordonez-Sanchez ${ }^{1, *}$, Robert Ellis ${ }^{1}$, Kate E. Porter ${ }^{1}$, Matthew Allmark ${ }^{1}$, Tim O'Doherty ${ }^{1}$, Allan Mason-Jones ${ }^{1}$, \\ Cameron Johnstone ${ }^{1}$
}

\begin{abstract}
As previously experienced by the wind industry, it is envisaged that tidal stream turbine blades will present misalignments or blade deformations over time as they are constantly working under harsh and highly unsteady environments. Blade misalignment will affect the power capture of a tidal stream turbine and if not detected in time could affect other components of the drive train. Therefore, the aim of this paper is to compare the use of two numerical modelling techniques to predict the performance of a tidal stream turbine working under off-design conditions, in this case, the misalignment of one or more blades. The techniques used in this study are Blade Element Momentum Theory and Computational Fluid Dynamics. The numerical models simulate the performance of a three-bladed horizontal axis tidal stream turbine with one or two blades offset from the optimum pitch setting. The simulations were undertaken at $1.0 \mathrm{~m} / \mathrm{s}$ flow speeds. The results demonstrated that both unsteady BEMT and steady or transient CFD are able to predict power coefficients when there is a certain level of misalignment in one or even two blades. However, both techniques failed to accurately predict a loss of power performance at high rotational speeds.
\end{abstract}

Keywords: Blade Element Momentum Theory, Computational Fluid Dynamics, Blade Misalignment, Off-design, Numerical Modelling, Tidal Stream Turbine

\section{Introduction}

According to the Clean Growth Strategy, the UK aims to promote a continuous growth in the economy while reducing greenhouse emissions [1]. Offshore marine renewables will play a crucial role to reach this objective, as the resource available in the

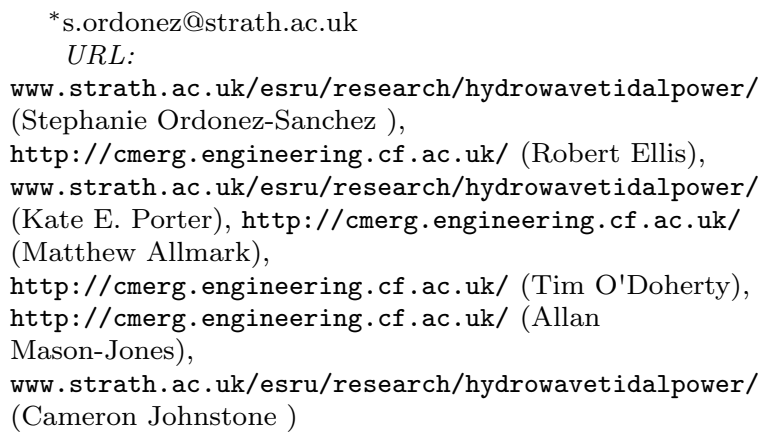

UK, from marine currents alone, is approximately 20.6 TWh ([2]). The main challenges arising with the implementation of tidal stream turbines (TSTs) are related to its performance, durability and reliability. As previously seen by the wind industry, major faults in wind turbines are associated with blades and blade root connections ([3], [4]). As found by [5] a faulty pitch mechanism in wind turbines could lead to an asymmetric load distribution inducing non-torque loads in the bearings and gearbox. But, other factors related to the flow structure could be as damaging as an existing fault. For example, it was observed in [6] that wind shear inflows generate out of plane bending causing a large shift in the line of action of the streamwise rotor forces, and thus, affecting the turbines structural integrity.

These faults are now becoming evident in Tidal Stream Turbines (TSTs). Atlantis resources re-

April 12, 2019 
cently announced that the pitching mechanism of one of the turbines had to be replaced due to its exposure to a long idle cycle [7]. It has also been observed at prototype scale that asymmetric loading due to unsteady flows and shadowing effects of the support structure can create changes in the axial force centroid [8]. In a similar a context, [9] highlighted that the accurate prediction of out of plane bending moments when a turbine is subjected to wave and currents is crucial in order to minimise internal bearing stresses in the turbines driveshaft.

In order to simulate rotor failures, [10] designed an experiment using a small scale TST, where one blade was fixed to the hub with an offset position compared to the optimum pitch setting. This experimental study proposed a methodology to study torque signal fluctuations to detect failures on the turbine. Although experimental work is highly valuable when studying complex fluid-structure interactions, the use of experimental tests can be restricted due to a number of reasons, such as the availability of the testing facility or adequate equipment. Therefore, an alternative solution is to use analytical or numerical modelling tools. In this paper we aim to use two of the most employed techniques in the tidal energy field, Blade Element Momentum Theory (BEMT) and Computational Fluid Dynamics (CFD).

\subsection{Blade Element Momentum Theory}

This method has been used widely to predict the performance of TSTs, e.g. [11], [12], [13]. It can be argued that BEMT is one of the least complex methods to compute the characteristics of a rotor while providing enough accuracy. The theory is based on the conservation of axial and angular momentum where axial and angular induction factors are derived unknowns from a set of equations. Momentum theory in itself does not take into account the characteristics of the rotor geometry, i.e. number of blades and the blade shape. Therefore, the momentum theory equations are coupled with blade element theory where an annular disk representing the turbine is split into several elements which are analysed independently in the radial direction. Using data for the $2-\mathrm{D}$ aerodynamic lift and drag coefficients for the blade aerofoil in question, these equations are solved iteratively to obtain the normal and tangential forces acting on each element of the blade section and in consequence the torque and thrust developed by the rotor.
The classic BEMT method can provide an adequate solution to model the performance of TSTs, but it is limited in certain respects. When used in its most basic form, BEMT does not take into account tip and hub losses, yaw inflow, turbulence, and in the case of the research presented here, blade offset conditions. However, modifications to the theory to address those limitations are available; some examples can be found in [14] and [15], to name only a few.

\subsection{Computational Fluid Dynamics}

Compared to BEMT, CFD is a numerical method based on the Navier Stokes equations. This method has been widely used to explore TST performance ([16], [17], [18], [19]), wake characteristics of single and multiple turbines [20], flow directionality [21] and wave-current interactions affecting single devices [22]. The main limitation with the use of $\mathrm{CFD}$ is the computational time required to compute complex dynamic simulations.

As depicted in Table 1, a few studies have made comparisons between BEMT and CFD in the field of marine energy. [17] and [18] found that CFD predicts marginally higher coefficients of power, thrust and torque than BEMT, even though the approaches were performed for two different types of TSTs, a cross flow turbine and a horizontal axis turbine, respectively. The analysis carried out by [16] showed that the CFD predictions compared to BEMT vary with the performance curve, and thus strongly depend on the tip speed ratio (TSR). Although under and over predictions were obtained in [16], it can be observed in the results a good level of agreement between the two methods.

As observed in Table 1, comparative analyses performed between CFD and BEMT have been completed using a wide range of model settings, especially when referring to CFD modelling. For example, [16] and [18] used k-omega Shear Stress Transport (SST) turbulence models in the simulations, whereas [19] used a k-epsilon model. Another feature is the boundary conditions specified in the model, i.e. slip conditions on the walls. But perhaps the main discrepancy between the models presented in Table 1 is related to the grid generation. Even though the majority of the investigations have used unstructured grids, [16] used a combination of elements by setting subdomains in the simulation, while [18] conducted a study to understand the implications of using different grid resolutions. [18] found that a coarser computational grid resulted in 
lower values of torque compared to those obtained with high resolution grids.

Little has been reported when comparing rotor or blade forces using both CFD and BEMT methods. [18] found that blade element momentum theory signicantly underestimates the hydrodynamic forces on the blade compared to the CFD solution. Major discrepancies when predicting blade forces at low tip-speeds were found by [17], which were associated with the approach used to model dynamic stall or its absence.

The investigations undertaken by the authors referenced in Table 1 have focused on comparisons related to performance of TSTs under steady flow conditions. According to the authors' knowledge, this comparative analysis has not been carried out for other operational conditions, especially those when the turbines performance is investigated during off-design conditions. Therefore, the aim of this paper is to determine the effects of blade offset on the performance of a TST using both CFD and BEMT models. The results of the simulations are then compared to experimental data sets to assess the capabilities of both numerical tools.

\section{Methodology}

A scaled three bladed horizontal axis turbine of $0.5 \mathrm{~m}$ diameter was used in this study. The aerofoil profile used was a Wortmann FX 63-137 and the blade chord and pitch distribution can be found in Figure 1. A flow regime of $1.0 \mathrm{~m} / \mathrm{s}$ was utilised in both CFD and BEMT simulations. According to experimental testing undertaken by [23] it was determined that Reynolds independence could be achieved for flow velocities equal or higher that 1.0 $\mathrm{m} / \mathrm{s}$.
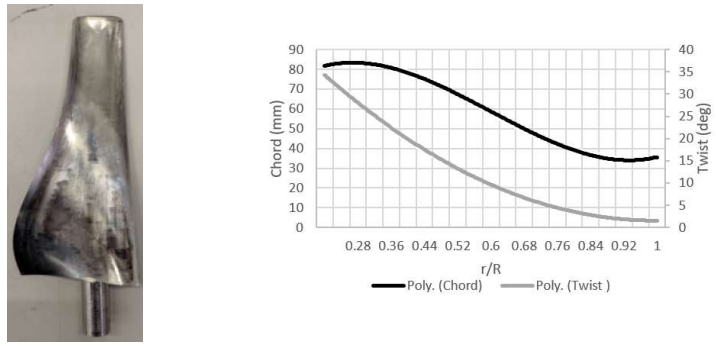

Figure 1: Wortmann FX63-137 airfoil used in the experiments and simulation. The chord and twist distribution can be found on the right hand side of the image.

Four cases were modelled in this study. The optimum case considers the scaled turbine with each of the three blades set to a pitch of $6^{\circ}$ based on the findings obtained in [24]. In that study, the authors carried out an investigation using CFD to evaluate the sensitivity of the power generated by a horizontal axis turbine to the blade pitch setting. A range of $6^{\circ}$ to $9^{\circ}$ pitch settings were modelled with all blades set to identical blade pitch. It was shown that the rotor was somewhat insensitive to changes in blade pitch angle with variations of power coefficient up to about $4.5 \%$ when the optimal angle was changed by $+3^{\circ}$. Therefore, two additional cases were also contemplated in this study with similar but also higher incremental offsets of $3^{\circ}$ and $6^{\circ}$ from the optimum setting, resulting on a final pitch setting of $9^{\circ}$ and $12^{\circ}$ for a single blade, respectively. To study a more complex configuration, an additional case was modelled in [23], where this time all blades were set with a different pitch. Blade 1 was modelled with the optimum pitch while blade 2 and blade 3 were set with a pitch of $9^{\circ}$ and $12^{\circ}$, respectively. In this paper, this case is refer as the $9^{\circ}+12^{\circ}$ case. A summary of the offset cases studied here is presented in Table 2 and a diagram of the cases can be observed in Figure 2 .
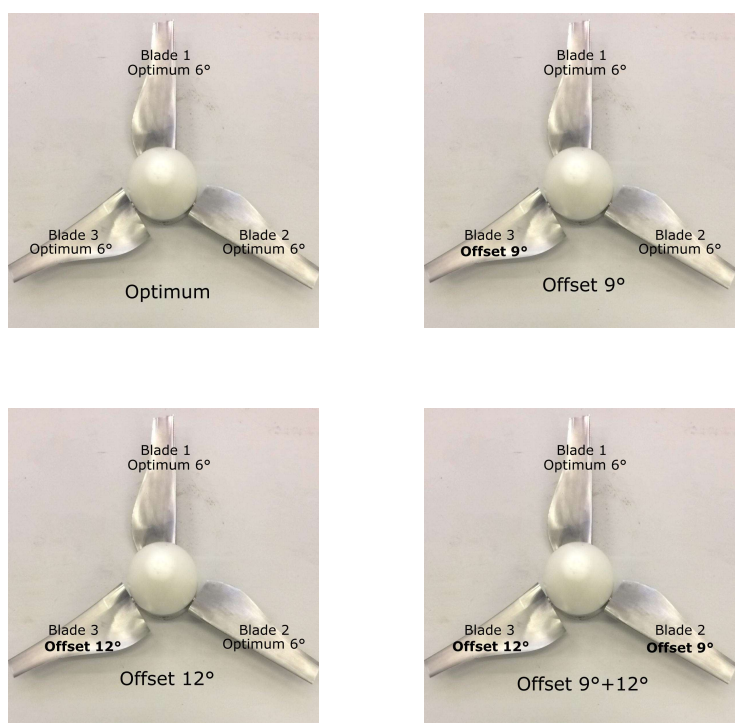

Figure 2: Diagram of the cases modelled in this study

Three non-dimensional parameters were used to compare the performance of the TST working under off-design conditions. The power $\left(C_{P}\right)$ and thrust coefficients $\left(C_{T}\right)$ were investigated as a function of tip speed ratio (TSR). These three parameters were quantified as follows: 
Table 1: Summary of computational fluid dynamic model settings used to compare the performance of tidal stream turbines with blade element momentum theory.

\begin{tabular}{|c|c|c|c|c|c|c|c|}
\hline Author & $\begin{array}{l}\text { Device } \\
\text { Type }\end{array}$ & $\begin{array}{l}\text { Simulation } \\
\text { Software }\end{array}$ & $\begin{array}{l}\text { Control } \\
\text { Volume }\end{array}$ & $\begin{array}{c}\text { Turbulence } \\
\text { Model }\end{array}$ & $\begin{array}{l}\text { Mesh/ } \\
\text { Grid }\end{array}$ & $\begin{array}{l}\text { No. of cells and } \\
\text { element type }\end{array}$ & Boundary condition \\
\hline $\begin{array}{l}\text { Johnson et } \\
\text { al. }\end{array}$ & CFT & Ansys CFX & - & $\begin{array}{c}\text { k-omega } \\
\text { SST }\end{array}$ & - & - & - \\
\hline Lee et al. & HAT & $\begin{array}{l}\text { Ansys } \\
\text { Fluent }\end{array}$ & $\begin{array}{c}\text { Inlet (3D), } \\
\text { Outlet } \\
\text { (6D) }\end{array}$ & $\begin{array}{c}\text { k-omega } \\
\text { SST }\end{array}$ & $\begin{array}{l}\text { Unstruc } \\
\text { tured }\end{array}$ & $\begin{array}{c}1.6 \text { million cell, } \\
\text { blade ( } \\
\text { tetrahedral } \\
\text { cells), simple } \\
\text { geometries } \\
\text { (hexahedral } \\
\text { cells) }\end{array}$ & $\begin{array}{c}\text { No slip on turbine } \\
\text { blade surfaces }\end{array}$ \\
\hline $\begin{array}{l}\text { Lawson et } \\
\text { al. }\end{array}$ & HAT & Star CCM & 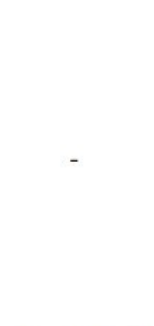 & $\begin{array}{c}\text { k-omega } \\
\text { SST }\end{array}$ & $\begin{array}{l}\text { Unstruc } \\
\text { tured }\end{array}$ & $\begin{array}{l}\text { Polyhedral } \\
\text { elements } \\
\text { having an } \\
\text { average of } 14 \\
\text { faces per } \\
\text { element }\end{array}$ & $\begin{array}{l}\text { Slip condition } \\
\text { across the curved } \\
\text { cylindrical surface } \\
\text { of the outer } \\
\text { domain. No slip on } \\
\text { all rotor surfaces. }\end{array}$ \\
\hline $\begin{array}{l}\text { Masters et } \\
\text { al. }\end{array}$ & HAT & $\begin{array}{l}\text { ANSYS } \\
\text { Fluent }\end{array}$ & $\begin{array}{l}\text { Inlet (10D), } \\
\text { Outlet } \\
(40 \mathrm{D}), \\
0.4 \% \\
\text { blockage } \\
\text { ratio } \\
\end{array}$ & $k-\varepsilon$ & $\begin{array}{l}\text { Unstruc } \\
\text { tured }\end{array}$ & $\begin{array}{c}\text { Tetrahedral } \\
\text { element }\end{array}$ & $\begin{array}{l}\text { No slip at the bed } \\
\text { and blade surfaces }\end{array}$ \\
\hline
\end{tabular}

Table 2: Pitch angle of each of the blades for the optimum and offset blade cases

\begin{tabular}{llll}
\hline Cases & Blade 1 & Blade 2 & Blade 3 \\
\hline 1 (Optimum) & $6^{\circ}$ & $6^{\circ}$ & $6^{\circ}$ \\
2 (Offset $\left.9^{\circ}\right)$ & $6^{\circ}$ & $6^{\circ}$ & $9^{\circ}$ \\
$3\left(\right.$ Offset $\left.12^{\circ}\right)$ & $6^{\circ}$ & $6^{\circ}$ & $12^{\circ}$ \\
$4\left(\right.$ Offset $\left.9^{\circ}+12^{\circ}\right)$ & $6^{\circ}$ & $9^{\circ}$ & $12^{\circ}$ \\
\hline
\end{tabular}

$$
C_{P}=\frac{P}{0.5 \rho A V^{3}}
$$

$$
\begin{gathered}
C_{T}=\frac{T}{0.5 \rho A V^{2}} \\
T S R=\frac{\omega r}{V}
\end{gathered}
$$

where $P$ and $T$ are the average power and thrust loads generated by the rotor, respectively. $A$ is the swept area of the rotor, and $V$ denotes the uniform, unidirectional flow velocity of $1.0 \mathrm{~m} / \mathrm{s}$ for this study. $r$ represents the radius of the rotor and $\omega$ is the angular velocity developed by the rotor in $\mathrm{rad} / \mathrm{s}$. $\rho$ is the density of the fluid which was set to 1000 $\mathrm{kg} / \mathrm{m}^{3}$. 


\subsection{Blade element momentum theory}

As mentioned in Section 1, BEMT combines momentum theory and blade element theory to compute the performance of a TST in terms of torque and thrust. To solve the set of equations derived from BEMT, the 2D lift $(\mathrm{Cl})$ and drag $(\mathrm{Cd})$ coefficients must be computed according to the type of aerofoil profile and flow conditions. Different approaches can be used to obtain these coefficients. While experimental testing of aerofoils can give an accurate prediction of lift and drag coefficients, the approach may be expensive and complex, especially if this is carried out in a flume tank. A simpler approach is to compute the coefficients using numerical methods, e.g. CFD, Xfoil, Profil 07, etc.

Xfoil is widely used in the field of marine and wind energy. It is based on a two-dimensional vortex panel code to evaluate the flow around aerofoils [25]. A few authors have compared the effects of using Xfoil to predict the performance of TSTs. [26] found that Xfoil accurately predicts $\mathrm{Cl}$ and $\mathrm{Cd}$ for high lift aerofoils at Reynolds numbers of around $2.0 \times 10^{5}$. Comparatively, [27] showed that XFoil under predicts $\mathrm{Cds}$ but predicts $\mathrm{Cls}$ within a reasonable margin, especially at angles of attack higher than $5^{\circ}-7^{\circ}$. Similarly, [28] showed that using Xfoil coefficients at low Reynolds numbers (Re $=4.4 \times 10^{5}$ ) resulted in poorer predictions compared to using experimental data in the model ( Re $\left.=5.1 \times 10^{4}\right)$. It is clear that as with any other numerical model, there are limitations with the use of Xfoil and the authors are aware of it. However, the $2 \mathrm{D}$ aerodynamic coefficients were obtained using Xfoil due to its ability to compute lift and drag coefficients for the flow conditions stated here. The Reynolds number considered for the simulations was $R e=1.1 \times 10^{5}$, measured at $75 \%$ of the blade span (from the centre outwards).

An unsteady BEMT model programmed at Strathclyde University [29] was used in this study. Prandtl tip and hub loss correction factors were utilised in order to account for the aerodynamic effects occurring near the tip and root of the blade. Classic BEMT assumes that the flow bypassing the turbine is within a streamtube and therefore, the axial induction factors are restricted to a value of less than 0.5 , according to $U_{w}=(1-2 a) V$; where and $U_{w}$ is the flow velocity of the wake and $a$ is the axial induction factor. To account for this limitation, [29] also included a Buhl correction formulation which allows the axial induction factor to be higher than the theoretical upper limit. The
Viterna-Corrigan method was also utilised to estimate high flow angles during post stall regions, especially used for highly loaded rotors with low aspect ratio blades [30]. This means that the aerofoil data that fall below the stall region are corrected to account for the finite blade length. The momentum equations for torque and thrust were divided by the number of blades so for each iteration a local induction factor was computed. However, the onset velocity considered in the simulations was uniform. A dynamic wake model correction was also included in the model based on [31].

\subsection{Computational fluid dynamics}

ANSYS CFX was used to model the scaled turbine described earlier. CFX solves the Reynolds averaged Navier-Stokes (RANS) equations which were closed using a $k-\omega$ SST turbulence model. The turbulence model was selected based on the experience of several authors who have found a close match between CFD computations and experimental work, e.g. [21].

The geometry was set up using the inbuilt CAD software Design Modeller. A control volume of $4 \mathrm{~m}$ (length) x $1.4 \mathrm{~m}$ (breadth) x $0.8 \mathrm{~m}$ (water depth) was used to represent the dimensions of the flume tank utilised in [32]. The rotor plane was located three diameters downstream from the inlet, five diameters upstream from the outlet and at mid-water level (Figure 3). The stanchion was also included in the CFD model and had a diameter of $90 \mathrm{~mm}$. The distance from the front of the stanchion to the back of the rotor plane was approximately $200 \mathrm{~mm}$. This distance was established to avoid regions of low flow velocity to attach the back of the blade ultimately affecting the performance of the rotor. This meant that the calculations carried out with BEMT were more comparable, as the BEMT model did not include any tower shadow effects. The blockage ratio was $17.5 \%$, which is similar to the experiments undertaken by [10]. The blockage effects on the performance of the turbine will be discussed in more detail in Section 3.

The next step in setting up the geometry was to conceive a methodology to modify the pitch angle without the need to fully reconstruct the turbine model. To modify the pitch angle of the blades within the geometry, three separate cylinders were drawn that encompassed each blade. The representation of the turbine compared to the physical model was attempted by separating the blades from the hub and attaching them using a pin, which was 


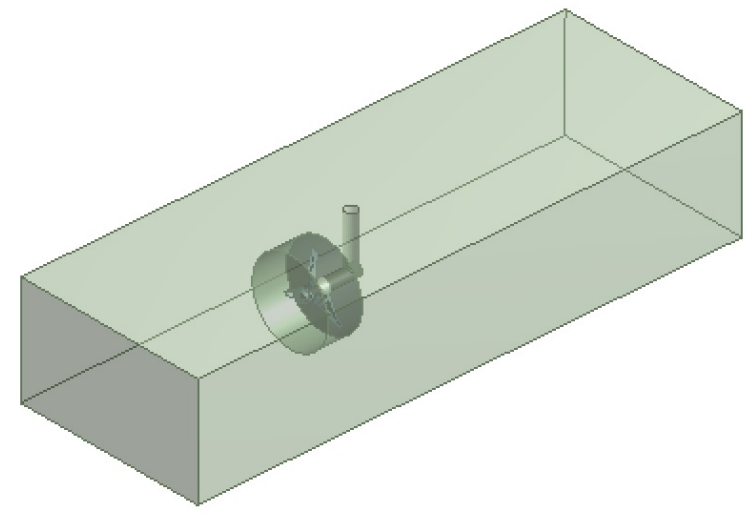

Figure 3: Control volume used in the CFD simulations.

the design proposed by [32]. An additional parameter was then considered to allow the free rotation of the blade about the pin, so the pitch offset was set according to each of the studied cases (Table 2). By using this method, the pitch offset was modified without the need to restructure the whole turbine geometry and it was more representative of the physical scaled turbine model. Blade 1, considered here as having an upright position when the model was initially set, was kept at $6^{\circ}$ pitch for all simulations. Blade 2 is considered here the second blade in the clockwise direction and Blade 3 the third, as shown in Figure 2.

To create the rotation of the turbine a moving reference frame (MRF) was used. The MRF was set as a cylinder of $0.6 \mathrm{~m}$ in diameter and was created around the turbine, as shown in Figure 4. For each of the simulations, the MRF was set to the angular velocity values of interest. A domain interface was used to pass the information between the cylinder and surrounding domain.

The mesh was configured with an unstructured tetrahedral mesh. Manual mesh refinement in the form of face sizing was placed on the turbine. The finest mesh was placed on the blades and increased from $0.001 \mathrm{~m} 0.0035 \mathrm{~m}$ as the mesh moved from tip to root. The maximum aspect ratio was 17 in the boundary layer on the blades, decreasing to less than 6 for all areas outside of the MRF and boundary layer regions. The mesh refinement was based on previous work done by [33] and [21] who undertook mesh independency analysis for this turbine geometry. The total number of elements in the domains was circa 2.3 million. The rotating domain contained most of the elements, around 1.5 million,

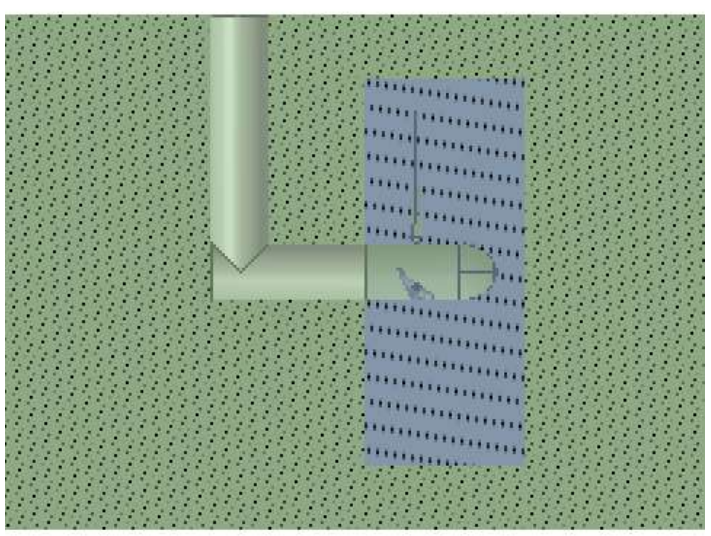

Figure 4: Turbine geometry implemented in CFD.

as this is the region of greatest interest. The wake dissipation was not studied in this paper and so the mesh in that region was left unrefined. The interface between the two domains was also refined so that a comparative mesh size was found on either side of the interface. This was done to help the preservation of terms across the interface, especially for the transient case which uses a sliding mesh approach which will be discussed in more detail below. These same mesh parameters were maintained for all the cases proposed in Table 2 .

The boundary conditions were set up using CFXPre. A uniform plug flow and a turbulence intensity of $10 \%$ were established at the inlet. When using RANS, the turbulence intensity dissipates rapidly throughout the domain. Consequently, in this model the turbulence intensity was approximately $2 \%$ near the turbine, which resembled the testing campaign. The boundaries of the control volume were set to no slip conditions for the walls with a pressure outlet at the end of the domain. The top of the domain was set up as an opening.

To model tidal stream turbines, it is common to use CFD in either transient or steady-state forms. The steady-state model uses a fixed mesh approach and produces one final time averaged solution i.e. it is a time independent solution. The turbine is fixed and is not rotating, rather the flow as it enters the MRF is rotated around the stationary turbine. The transient approach uses a sliding mesh and the results can be monitored with respect to 
time throughout the rotation of the turbine i.e. the turbine and mesh are rotating with each timestep as seen in real life. Due to the increased complexity in the transient solution the computational power and time required is increased. In this study, both steady state and transient analyses were undertaken to compare the effectiveness of each method against the computational time and power consumed to perform each of the simulations.

For the comparison between steady and transient analysis only one TSR value was explored, that of peak power for the turbine. This value was chosen as this region of the turbine has been characterised well in previous studies, both numerically and experimentally $([21],[34])$. The results of these analyses are shown in Section 3. The timestep was taken as $0.005 \mathrm{~s}$ and run for a total time of $30 \mathrm{~s}$ to allow for convergence. If the timestep was to be selected based on the smallest cell size, then it would need to be in the order of 0.001s. As such, the timestep was increased slowly to $0.005 \mathrm{~s}$. It was found that there was no change between the results for the two timesteps however the simulation finished almost ten times faster when a timestep of $0.005 \mathrm{~s}$ was used. The timestep was not increased beyond this value so that the rotation of the turbine could still be captured to a relatively high accuracy as the turbine rotated 4 degrees per timestep. The corresponding CFL number for this timestep was around 50 .

\subsection{Experimental tests}

The results obtained from CFD and BEMT were compared with the experimental data obtained in [10] who used a $0.5 \mathrm{~m}$ diameter TST. The scaled turbine was installed in a flume facility with a working section of $3.7 \mathrm{~m}$ (length) x $1.4 \mathrm{~m}$ (breadth) x 0.8 $\mathrm{m}$ (water depth). The turbine and control volume described in Section 2.2 were of similar geometry and dimensions to the physical scaled model. As mentioned earlier, the blockage ratio calculated for the experiments was $17.5 \%$. The turbine was installed $0.42 \mathrm{~m}$ below the water surface so the hub centre sat close to mid water level. The turbulence intensity at the facility was recorded as $2 \%$ for flow velocities between 0.5 and $1.5 \mathrm{~m} / \mathrm{s}$, according to [35]. To obtain the performance curve of the rotor, a motor (in combination with an encoder) was programmed to hold the rotor speed at a number of constant values. The torque generating current (TGC) was logged from the motor to estimate power output. The effects of friction in the drive shaft were determined prior to the test campaign and subtracted from the TGC to quantify the real torque generated by the rotor. This was done by logging the TGC in a water basin and running the motor at several speeds without the blades. This experimental procedure can be found in [34]. The power data was not corrected for blockage as the CFD model was constructed to replicate the experiment. The testing campaign carried out by [10] did not involve the measurement of thrust for the full rotor and therefore the numerical models are not compared to experimental data when analysing the $C_{T}$ values.

\section{Results and Discussion}

This section presents the comparative results between BEMT, CFD (steady and transient models) and when possible with experimental data. The results are shown in terms of power $\left(C_{P}\right)$ and thrust $\left(C_{T}\right)$ coefficients over a range of TSRs in Figures 5-8. Figures 9-11 show the difference between the optimum and the offset cases.

\subsection{Steady and Transient CFD results}

As mentioned in Section 2, the turbine operating under off-design conditions was modelled in CFD using steady-state and transient methods. Table 3 shows the results of the comparative analysis for both CFD models for Case 1. It can be observed that there is a discrepancy of less than $3 \%$ for both $C_{P}$ and $C_{T}$. Cases 2-4 were also compared but even though the difference between the transient and the steady state CFD model increased slightly, this was never higher than 5\% as can be seen in Figures 5-8. The total length of time to solve each of the transient models was 10 hours. The models were run for 20 seconds with time steps of 0.05 seconds. In contrast, it only took 3 hours to reach convergence for the steady state models which converged in less than 2000 iterations. Therefore, the steady state model was used for the remaining cases at several TSRs.

Table 3: Coefficients of Power and Thrust calculated from the CFD Model for the Optimum Blade Pitch Case at $\mathrm{TSR}=3.6$

\begin{tabular}{llll}
\hline Model & $C_{P}$ & $C_{T}$ & Solving time \\
\hline Transient CFD & 0.40 & 0.78 & 10 hours \\
Steady-State CFD & 0.39 & 0.76 & 3 hours \\
\% difference & 3.5 & 2.3 & \\
\hline
\end{tabular}




\subsection{Power Coefficient}

Both BEMT and CFD models provide a reasonable prediction when considering the $C_{P}$ values of the optimum condition compared with the experiment (Figure 5), giving confidence that both models work effectively. For the cases including a single blade offset $\left(9^{\circ}\right.$ or $\left.12^{\circ}\right)$ and within TSR values of 2.5 to 4.5 , the difference in predictions between models and experiment are $<10 \%$. This agreement becomes poorer as the turbine operates close to freewheel condition, especially when observing the predictions from CFD which over predict the power coefficients to twice the value compared to the experimental data.

An additional case is included in this section to investigate the effects of alternating the blade offset between blades 2 and 3 (for the Offset $9^{\circ}+12^{\circ}$ case and using a CFD transient analysis). Initially, the Offset $9^{\circ}+12^{\circ}$ case was computed by setting Blade $1=6^{\circ}$, Blade $2=9^{\circ}$ and Blade $3=12^{\circ}$; in contrast, the Offset $12^{\circ}+9^{\circ}$ case is now explored by setting Blade 2 to $12^{\circ}$ and Blade 3 to $9^{\circ}$. Little disagreement was found between the results of both cases, see Table 4; therefore, no more attempts to model additional TSR cases were made.

The experimental data used in the comparison with both numerical models contains some uncertainty associated with the measurements. This uncertainty was reported to be as high as $6 \%$ for some of the torque measurements, see [36]. Therefore, a good level of agreement has been reached between the experimental and the simulation models for the majority of the cases. It is worth noting that the experimental results were not corrected for blockage as the CFD models were defined to reproduce the experimental tests and the BEMT model used in this investigation did not take into account blockage or surface effects.

Table 4: Coefficients of Power and Thrust calculated from the CFD Model for the Optimum Blade Pitch Case at $\mathrm{TSR}=3.6$

\begin{tabular}{lll}
\hline Model & $C_{P}$ & $C_{T}$ \\
\hline Offset $9^{\circ}+12^{\circ}$ & 0.386 & 0.88 \\
Offset $12^{\circ}+9^{\circ}$ & 0.388 & 0.89 \\
\hline
\end{tabular}

\subsection{Thrust coefficient}

The results for $C_{T}$ obtained with $\mathrm{CFD}$ and BEMT showed good agreement when comparing the optimum case for all the TSR values (Figure 5,bottom). However, when comparing the offset cases, there is a large discrepancy between the models (Figures 6-8(bottom)). This discrepancy also increases with TSR values where the worst disagreement was found for Offset $9^{\circ}+12^{\circ}$ case and $\mathrm{TSR}=5.5$ with $\mathrm{CFD}$ values being twice as high as those predicted with BEMT.

Even though BEMT is considered an acceptable tool to predict the performance of wind and tidal energy converters, there are several limitations associated with its use. One reason associated with the discrepancy of thrust values may be related to the corrections used in the model. However, when looking at the angles of attack generated for the optimum and offset cases, it was observed that those never exceeded stall regions, and therefore, it is unlikely that the Viterna-Corrigan method had any impact on the predictions shown here.

An additional reason for a high discrepancy between models may be partly because the BEMT model in this investigation does not account for blockage or free surface corrections. It has been observed in [37] and [38] that the performance of a turbine in a blocked environment is more affected when looking at thrust coefficients rather than power coefficients. [38] highlighted that there was only $1 \%$ of difference when comparing maximum $C_{P}$ in unblocked and blocked environments. However, thrust values were almost twice as large in blocked environments. And, the blocked conditions in that study resemble the case studied here (approximately 19\%).The conclusion derived from that study was that the rotor needs to apply greater than optimal thrust on the flow to achieve maximum power. This in turn results in a larger than optimal reduction in momentum downstream.

However, the main limitation with the use of BEMT in its current form to predict offset cases is that this method assumes blade and element independence. Even when an unsteady BEMT was employed, it was found that the resultant torque and thrust were similar as if the loads computed for different blade pitch settings were combined proportionally; e.g. $2 / 3$ of the torque and thrust from the optimum condition added to a $1 / 3$ of the resultant torque and thrust for the $9^{\circ}$ offset case (as it was previously done in [39]). It is likely that differences between BEMT and CFD are because the circulatory fluid component from neighbouring blades and wakes is not taken into account in the BEMT model used and thus, this unequal strengths related to vortex shedding may influence the thrust loads seen by 
the rotor giving larger thrust loads, as predicted in CFD. One way to overcome this limitation would be to incorporate methods to take into account the vortex shedding from the blades, as suggested by [40] and [41]. These alternative methods are out of the scope of this investigation but will be considered in the future.
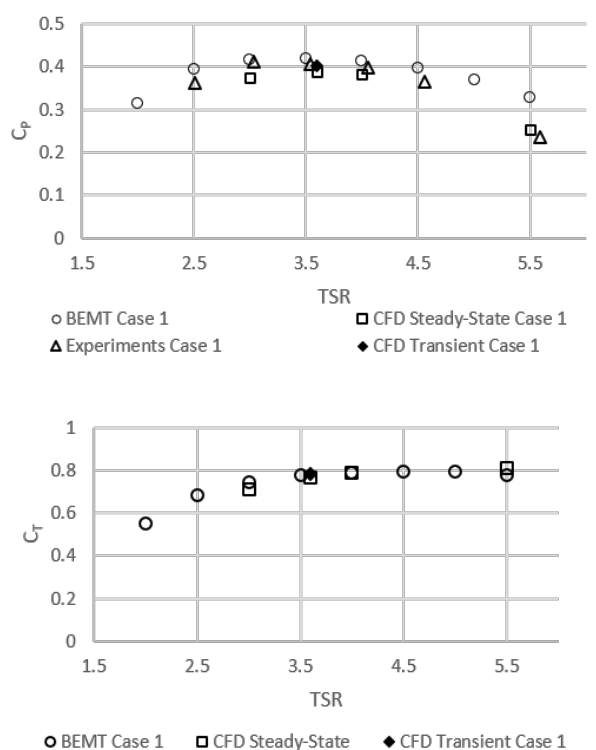

Figure 5: CFD, BEMT and experimental results showing (top) $C_{P}$ and (bottom) $\mathrm{CT}$ at $1.0 \mathrm{~m} / \mathrm{s}$ for the Optimum case.

\subsection{Variation of power and thrust coefficients be- tween optimum and offset cases}

To understand if both models predict the same proportion of $C_{P}$ and $C_{T}$ lost or gained when the turbine operated under off-design conditions, the difference between the optimum and the offset results is presented in Figures 9-11. The $C_{P}$ variation for Offset $9^{\circ}$ and Offset $12^{\circ}$ cases is in close agreement, especially for TSRs $<4.5$. The differences between the optimum and offset cases calculated by the simulations are smaller than those obtained from the testing campaign. This again can be attributed to disturbances in the flow created by the offset blades on the wake. In terms of $C_{T}$ variation, the two numerical approaches predict completely opposite behaviours when studying the differences between the optimum and offset cases. It was predicted by BEMT that there would be a loss of $C_{T}$ of about $50 \%$ when offsetting one or two blades in the turbine in the worst case scenario (Offset $9^{\circ}+12^{\circ}$
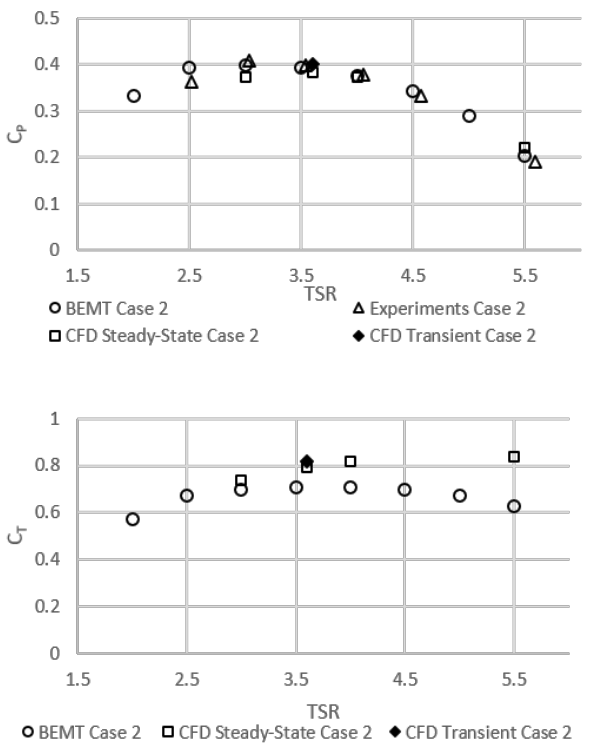

Figure 6: CFD, BEMT and experimental results showing (top) $C_{P}$ and (bottom) $C_{T}$ at $1.0 \mathrm{~m} / \mathrm{s}$ for the $9^{\circ}$ Offset case.
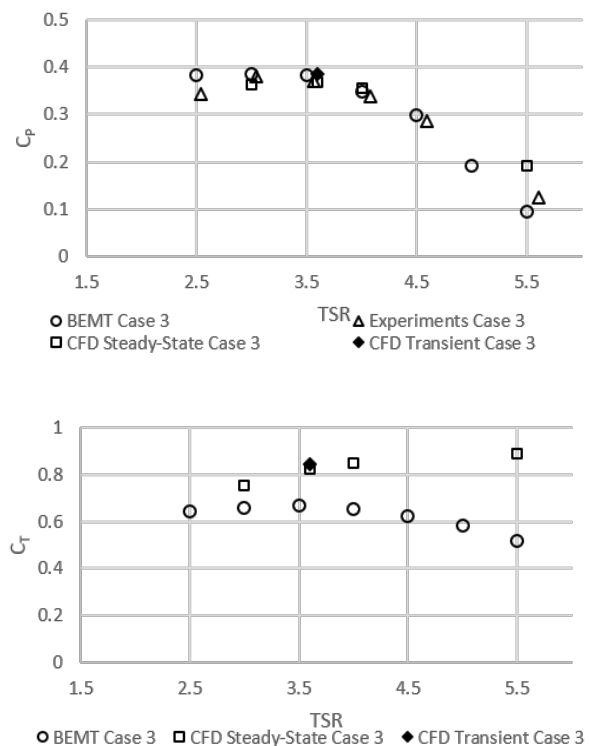

Figure 7: CFD, BEMT and experimental results showing (top) $C_{P}$ and (bottom) $C_{T}$ at $1.0 \mathrm{~m} / \mathrm{s}$ for the $12^{\circ}$ Offset case.

case and a TSR=5.5). In contrast, both steadystate and transient CFD models predict that the thrust of the rotor would increase when working under off-design conditions. 

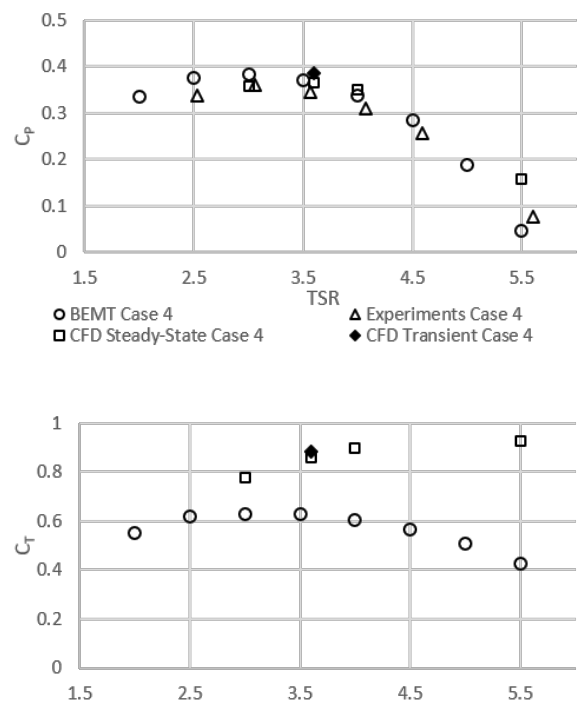

o BEMT Case 4 a CFD Steady-State TSBe $4 \bullet$ CFD Transient Case 4

Figure 8: CFD, BEMT and experimental results showing (top) $C_{P}$ and (bottom) $C_{T}$ at $1.0 \mathrm{~m} / \mathrm{s}$ for the $9^{\circ}+12^{\circ}$ Offset case.
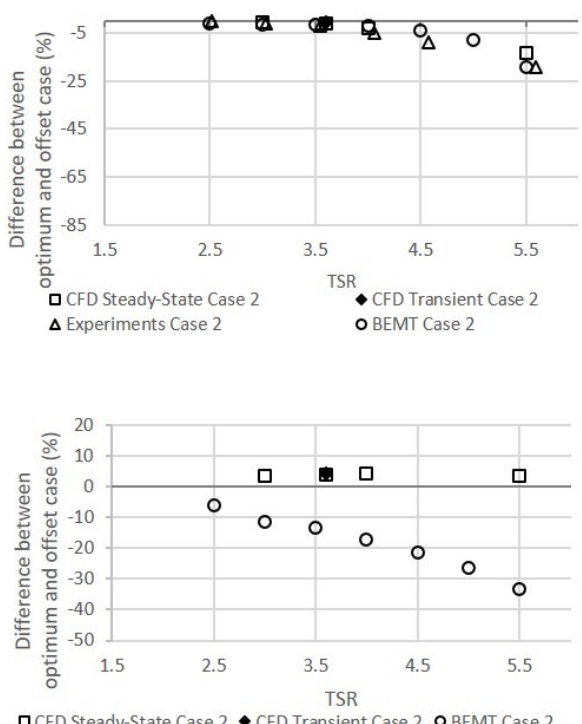

Figure 9: Difference in percentage of the (top) $C_{P}$ and (bottom) $C_{T}$ between the optimum and the $9^{\circ}$ Offset case.

\subsection{Torque and thrust variations per blade}

The average torque and thrust values per blade from the transient CFD model are shown in Figure 12. It is noticeable that the offset blade affected both the torque and thrust seen by the adjacent
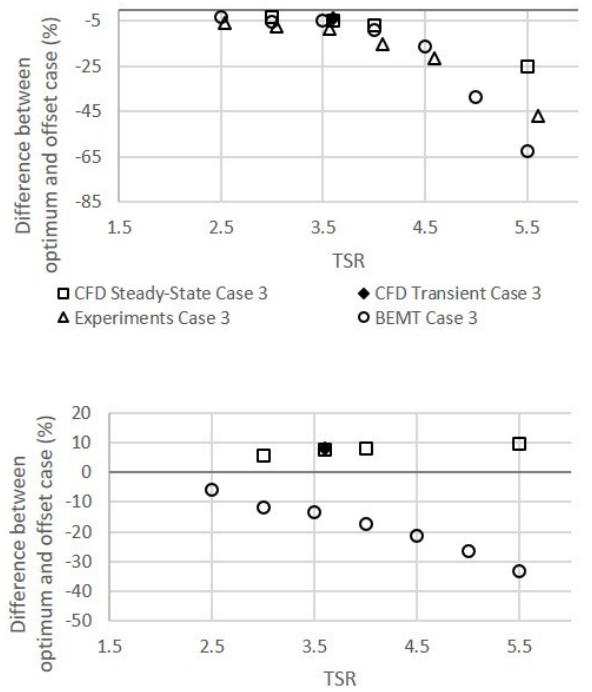

口 CFD Steady-State Case $3 \bullet$ CFD Transient Case 3 O BEMT Case 3

Figure 10: Difference in percentage of the (top) $C_{P}$ and (bottom) $C_{T}$ between the optimum and the $12^{\circ}$ Offset case.
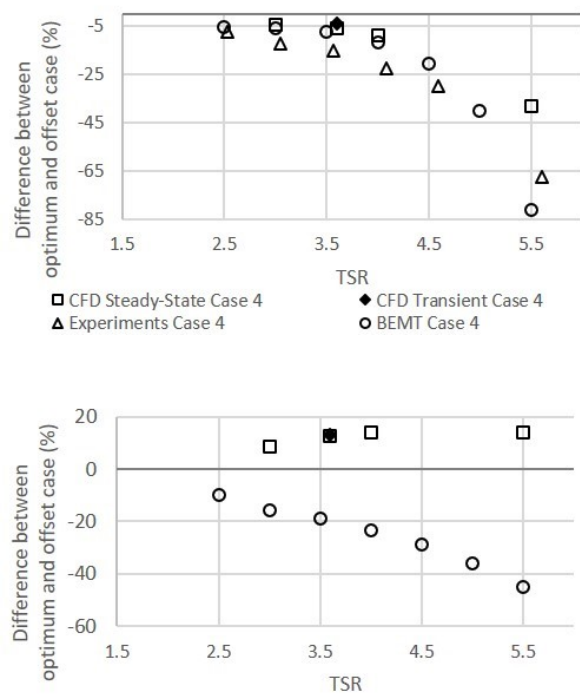

口 CFD Steady-State Case $4 \bullet$ CFD Transient Case 4 O BEMT Case 4

Figure 11: Difference in percentage of the (top) $C_{P}$ and (bottom) $C_{T}$ between the optimum and the $9^{\circ}+12^{\circ}$ Offset case (2 bladed Offset).

blades. The highest drop on torque coefficient is developed in Blade 3 for the 2 bladed offset cases and Blade 2 for the Offset $12^{\circ}$. A similar trend can be observed for the thrust coefficients where the highest thrust is developed in Blade 2 during 
the Offset $9^{\circ}+12^{\circ}$ case. Blade 1 develops a similar thrust value in the Offset $12^{\circ}$ and $9^{\circ}+12^{\circ}$ cases. Also, all the cases with a $12^{\circ}$ offset blade developed the largest amplitude of torque and thrust variation, 0.002 and 0.11 , respectively, even if there is only one misaligned blade.

The torque and thrust variation through time obtained from the transient CFD study is analysed in Figure 13. The variation was calculated using the maximum and minimum values extracted from the transient models which were run for a total time of $30 \mathrm{~s}$ (see Appendix A). As before, the offset blade has a noticeable influence on the torque and thrust variation occurring in the adjacent blades. The largest torque and thrust variation observed was that of Blade 3 in the Offset $9^{\circ}+12^{\circ}$ case. The second greatest torque and thrust variation was that of Blade 2 for the Offset $12^{\circ}$ case, again highlighting that these variations seemed to be more affected by having a very large offset on a single blade than for example, having potentially two offset blades with a small misalignment.

The time series of the combined thrust and torque forces developed by each of the blades can be found in Figure 14. As mentioned in Section 1, it is expected that the rotor will be subjected to an uneven load distribution when the pitch setting of one or more blades changes from the optimum position. When the optimum case was compared to the Offset $12^{\circ}+9^{\circ}$, the mean thrust increased by $13 \%$ and the mean torque decreased by $4 \%$. And, the mean fluctuating thrust and torque for the same case was in the order of $3.5 \%$ and $12 \%$, respectively.

Asymmetrical rotor loading can also occur due to external factors, for example shear flows. According to [42], when a turbine is subjected to turbulence intensities of about $17 \%$ and length scales of $0.41 \mathrm{~m}$, thrust and torque fluctuations in the range of $18-20 \%$ and $25 \%$, respectively, can occur in a TST. [43] showed that when a turbine operates under combined currents and medium size waves, thrust and torque fluctuations of $27 \%$ and $40 \%$ can be produced in the rotor. An additional factor that can produce asymmetrical loading in a turbine is the supporting mechanism. In that context, [44] showed that by analysing a turbine with and without tower, the fluctuating thrust developed by a turbine can increase from $3 \%$ to $10 \%$. These figures were calculated using the maximum and minimum values over the mean included in [44].

By comparing those figures with the outcomes of this investigation, it can be observed that the effects related to the flow characteristics can be more detrimental for a tidal stream turbine than by having an uneven distribution of pitch settings per blade. However, investigations related to the effects that an offset pitch produce in the out of plane bending moment should be consider in the future, as these have shown to affect internal stresses in the drivetrain of a turbine, as studied by [9].

\section{Conclusions and Future Work}

A comparative analysis using numerical models was carried out to predict the performance of a tidal turbine when turbine blades operate under offdesign conditions. It was found that both CFD and BEMT were able to predict the power loss of a small scale turbine when it operated with one or even two offset blades at a flow velocity of $1.0 \mathrm{~m} / \mathrm{s}$. The difference between models and experiment was $<10 \%$ for most of the simulations, especially when looking at peak conditions. The major discrepancy seen in the power coefficients was at high TSRs when the turbine operated near the freewheel region.

When looking at the differences between the optimum and offset cases, both numerical models and the experimental data for $C_{P}$ showed similar variations except for the 2 bladed case $\left(9^{\circ}+12^{\circ}\right)$. The variations obtained in the $9^{\circ}+12^{\circ}$ case between models and experiment were slightly higher with a difference of about $30 \%$ in the region below $\mathrm{TSR}=4.5$.

The numerical models showed poorer agreement between each other when comparing $C_{T}$. It was concluded that the main limitation associated with the BEMT model is that the circulatory fluid component from neighbouring blades and wakes is not taken into account and thus, unequal strengths related to vortex shedding may influence the thrust loads seen by the rotor giving larger thrust loads, as predicted in CFD. Up to a certain extent, the high blockage conditions modelled by CFD and the experiment, were not included in BEMT which may had a great impact in the thrust predictions. Thus, future work will focus on exploring alternative methods to incorporate blade misalignment in BEMT and additional physical modelling will be carried out in low blockage ratio environments.

The data obtained from the transient analysis for a small scale 3-bladed device showed that the case with single blade with a large offset blade, can induce similar torque and thrust variations, as those obtained in the cases with two offset blades (where 

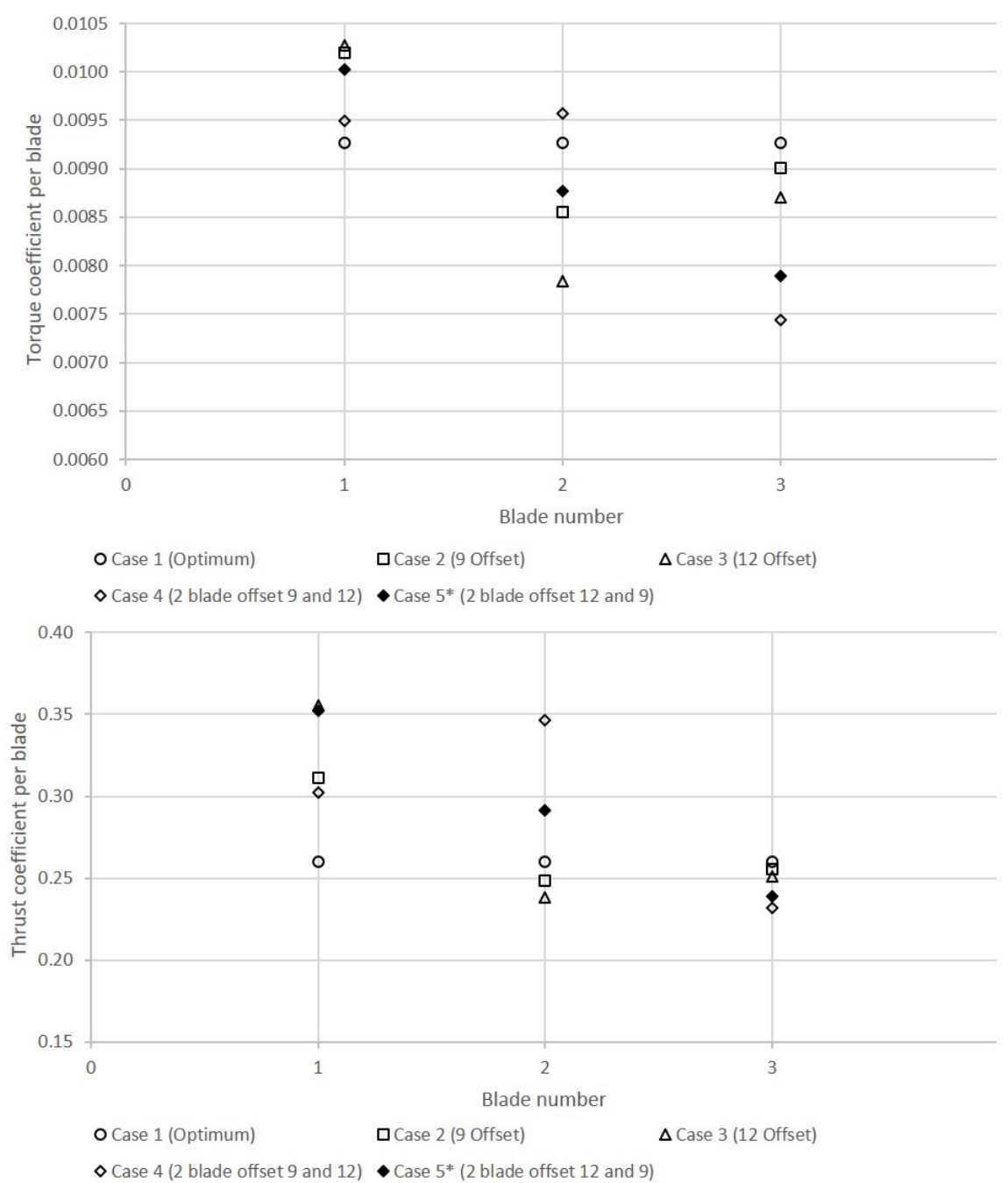

Figure 12: Mean (top) torque and (bottom) thrust blade results obtained from CFD transient analysis at TSR=3.6

one of the blades has the same pitch as the single offset blade). It was also shown that the variation of torque and thrust produced by an uneven distribution of pitch settings in a rotor can be in the order of $12 \%$ and $3.5 \%$, respectively. And even though this is a significant variation of loading, other factors in the flow structure such as turbulence or waves can produce variations of torque and thrust higher than $20 \%$. It must be noted that such comparisons did not consider considered out of plane loadings which could potentially be more detrimental to the drivetrain of a TST.

The experimental data used to validate the models employed a Wortmann aerofoil which is deemed to be less sensitive to changes in pitch. It is possible that a different blade shape will produce different torque and thrust variations when working under off-design conditions. Future work will contemplate the importance of the blade profile on the performance of the turbine when one or two blades have a misalignment.

\section{Acknowledgements}

The authors would like to acknowledge EPSRC $\mathrm{EP} / \mathrm{N} 020782 / 1$ for funding this research.

\section{References}

[1] E. . I. S. Department for Business, Clean growth strategy: executive summary. (2018).

URL https://www.gov.uk/government/ 

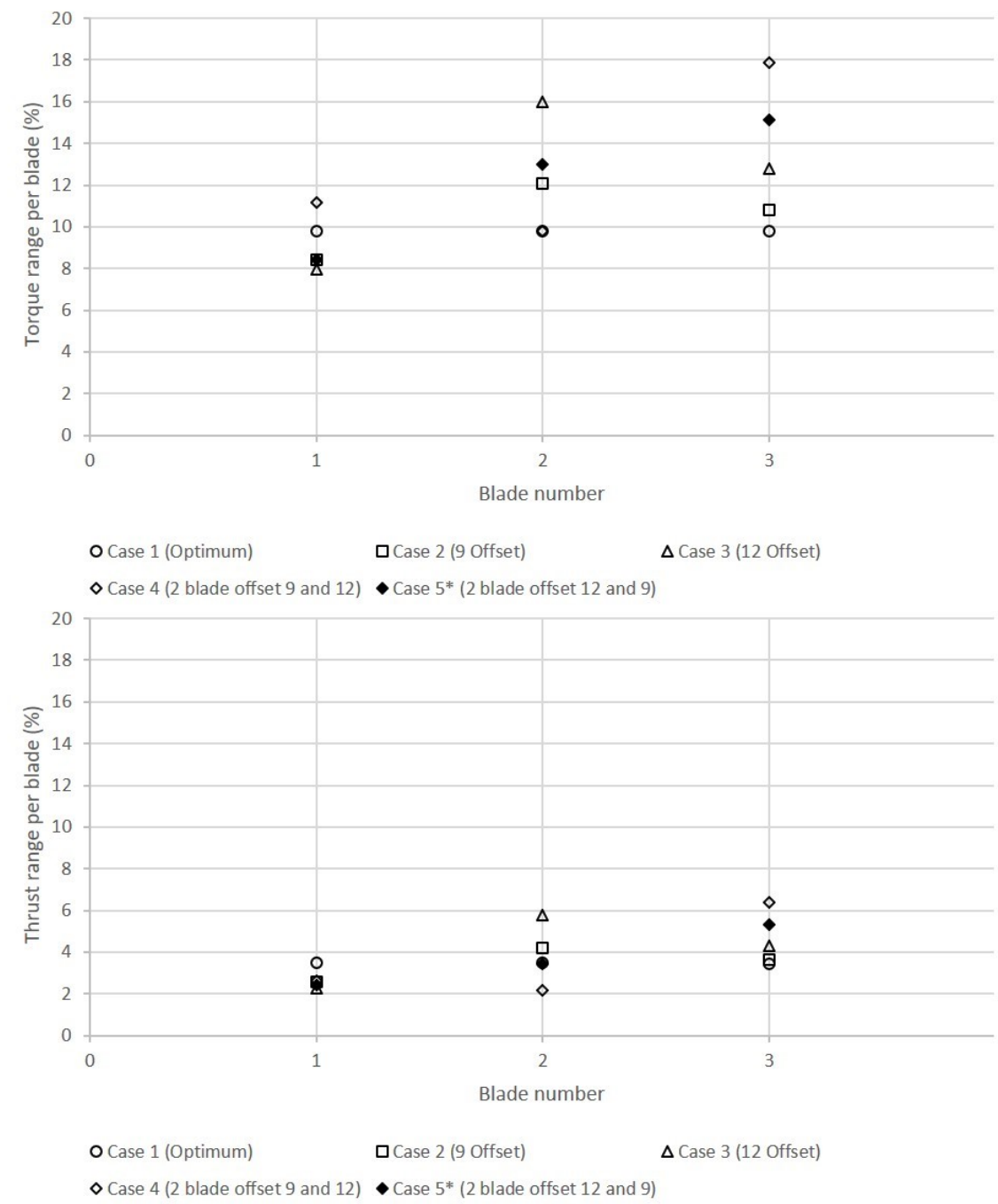

Figure 13: Difference between the maximum and minimum (top) torque and (bottom) thrust blade data variations obtained from CFD transient analysis at $\mathrm{TSR}=3.6$

publications/clean-growth-strategy/ clean-growth-strategy-executive-summary.

[2] B. . Veatch, Carbon trust foreword to uk tidal current resource and economics study (2011).

[3] A. Kusiak, A. Verma, A data-driven approach for monitoring blade pitch faults in wind turbines, IEEE Transactions on Sustainable Energy 2.

[4] S. Cacciola, I. M. Agud, C. L. Bottasso, Detection of rotor imbalance, including root cause, severity and location, Journal of Physics: Conference Series 753 (2016) 072003 doi:10.1088/1742-6596/753/7/072003.

[5] A. R. Nejad, Z. Jiang, Z. Gao, T. Moan, Drivetrain load effects in a 5-mw bottom-fixed wind turbine under blade-pitch fault condition and emergency shutdown, Journal of Physics: Conference Series 753 (11) (2016) 112011.

URL http://stacks.iop.org/1742-6596/753/i=11/a= 112011

[6] D. Micallef, T. Sant, Rotor aerodynamics in sheared inflow: An analysis of out-of-plane bending moments, Journal of Physics: Conference Series 1037 (2) (2018) 022027.

URL http://stacks.iop.org/1742-6596/1037/i=2/a= 022027

[7] Atlantis resources (Oct. 2017).

URL https://www.atlantisresourcesltd.com/

[8] G. S. Payne, T. Stallard, R. Martinez, T. Bruce, Variation of loads on a three-bladed horizontal axis tidal turbine with frequency and blade position, Journal of Fluids and Structures 83 (2018) $156-170$. doi : https: //doi.org/10.1016/j.jfluidstructs.2018.08.010. URL http://www.sciencedirect.com/science/ article/pii/S0889974617306734

[9] T. Nevalainen, D. Peter, C. Johnstone, Internal bearing stresses of horizontal axis tidal stream turbines operating in unsteady seas., 3rd Asian Wave and Tidal Energy Conference, 2016.

[10] M. Allmark, Condition Monitoring and Fault Diagnosis 

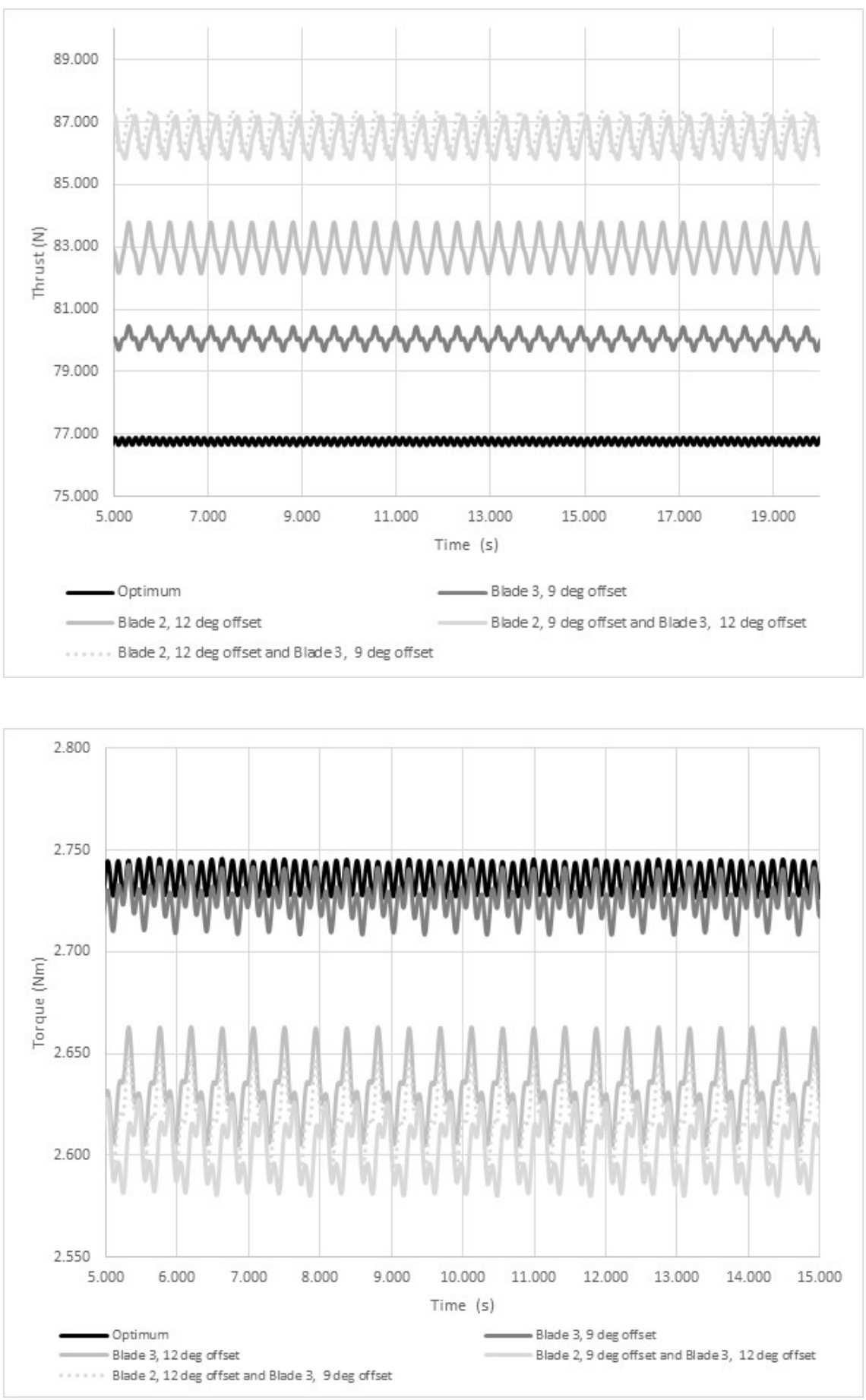

Figure 14: Thrust (top) and torque (bottom) developed by the horizontal turbine for each of the cases studied here using CFD transient analysis at $\mathrm{TSR}=3.6$

of Tidal Stream Turbines Subjected to Rotor Imbalance Faults, Cardiff University, Cardiff Marine Energy
Research Group., 2017.

[11] I. Masters, J. C. Chapman, J. A. C. Orme, M. R. Willis, 
A robust blade element momentum theory model for tidal stream turbines including tip and hub loss corrections, Proceedings of the Institute of Marine Engineering, Science and Technology Part A Journal of Marine Engineering and Technology 10 (2011) 23-35.

[12] P. Galloway, L. Myers, A. A. Bahaj, Quantifying wave and yaw effects on a scale tidal stream turbine, Renewable Energy 63 (2014) 297-307.

[13] T. M. Nevalainen, C. M. Johnstone, A. D. Grant, A sensitivity analysis on tidal stream turbine loads caused by operational, geometric design and inflow parameters, International Journal of Marine Energy 16 (2016) 5164.

[14] P. Galloway, Performance Quantication of Tidal Turbines Subjected to Dynamic Loading, University of Southampton, 2013.

[15] M. Togneri, I. Masters, J. Orme, Incorporating turbulent inflow conditions in a blade element momentum model of tidal stream turbines, Proceedings of the 21st International Offshore and Polar Engineering Conference, 2011.

[16] J. H. Lee, S. Park, D. H. Kim, S. H. Rhee, M. C. Kim, Computational methods for performance analysis of horizontal axis tidal stream turbines, Applied Energy 98 (2012) 512-523.

[17] P. B. Johnson, G. I. Gretton, T. McCombes, Numerical modelling of cross-flow turbines: a direct comparison of four prediction techniques, 3rd International Conference on Ocean Energy, 3rd International Conference on Ocean Energy, 2010.

[18] M. J. Lawson, Y. Li, D. C. Sale, Development and verification of a computational fluid dynamics model of a horizontal-axis tidal current turbine, ASME 30th International Conference on Ocean, Offshore, and Arctic Engineering, 2011.

[19] I. Masters, A. Williams, T. N. Croft, M. Togneri, M. Edmunds, E. Zangiabadi, I. Fairley, H. Karunarathna, A comparison of numerical modelling techniques for tidal stream turbine analysis, Energies (2015) 7833-7853.

[20] M. G. Gebreslassie, S. O. Sanchez, G. R. Tabor, M. R. Belmont, T. Bruce, G. S. Payne, I. Moon, Experimental and cfd analysis of the wake characteristics of tidal turbines, International Journal of Marine Energy 16 (2016) 209-219.

[21] C. Frost, C. E. Morris, A. Mason-Jones, D. M. O'Doherty, T. O'Doherty, The effect of tidal flow directionality on tidal turbine performance, Renewable Energy 78 (2015) 609-620.

[22] S. C. Tatum, C. H. Frost, M. Allmark, D. M. ODoherty, A. Mason-Jones, P. W. Prickett, R. I. Grosvenor, C. B. Byrne, T. ODoherty, Wavecurrent interaction effects on tidal stream turbine performance and loading characteristics, International Journal of Marine Energy.

[23] M. Allmark, R. Grosvenor, P. Prickett, An approach to the characterisation of the performance of a tidal stream turbine, Renewable Energy 111 (2017) 849 - 860. doi: https://doi.org/10.1016/j.renene.2017.05.010. URL http://www.sciencedirect.com/science/ article/pii/S0960148117303956

[24] T. ODoherty, A. Mason-Jones, D. Doherty, C. Byrne, I. Owen, Y. Wang, Experimental and computational analysis of a model horizontal axis tidal turbine, Proceedings of the 8th European Wave and Tidal Energy Conference EWTEC, 2009.
[25] M. Drela, XFOIL an analysis and design system for low Reynolds number airfoils, in: T.J. Mueller (Ed.), Low Reynolds Number Aerodynamics, Springer-Verlag, 1989.

[26] J. Morgado, R. Vizinho, M. A. R. Silvestre, J. C. Pscoa, Xfoil vs cfd performance predictions for high lift low reynolds number airfoils, Aerospace Science and Technology 52 (2016) 207214.

[27] A. F. Molland, A. S. Bahaj, J. R. Chaplin, W. M. J. Batten, Measurements and predictions of forces, pressures and cavitation on 2-d sections suitable for marine current turbines., Proceedings of the Institution of Mechanical Engineers, Part M: Journal of Engineering for the Maritime Environment 218 (2004) 127-138.

[28] K. Porter, S. Ordonez-Sanchez, T. Nevalainen, S. Fu, C. Johnstone, Comparative study of numerical modelling techniques to estimate tidal turbine blade loads, 3rd Asian Wave and Tidal Energy Conference, 2016.

[29] T. M. Nevalainen, C. M. Johnstone, A. D. Grant, An unsteady blade element momentum theory for tidal stream turbines with morris method sensitivity analysis, Proceedings of the 11th European Wave and Tidal Energy Conference, EWTEC, 2015.

[30] D. A. Spera, Wind Turbine Technology: Fundamental Concepts in Wind Turbine Engineering, Second Edition, ASME, 2009.

[31] M. O. L. Hansen, Aerodynamics of Wind Turbines: Rotors, Loads and Structure, Aktuelle Problems in der Angiologie, James \& James, 2000.

URL https://books.google.co.uk/books?id=d_ REBCyBuKkC

[32] M. Allmark, R. Grosvenor, P. Prickett, C. Frost, The specification of and testing of a horizontal axis tidal turbine rotor monitoring approach, PHM Society. International Journal of Prognostics and Health Management (9).

URL http: //www.phmsociety.org/node/2530

[33] A. Mason-Jones, Performance assessment of a horizontal axis tidal turbine in a high velocity shear (2013).

[34] S. Ordonez-Sanchez, K. Porter, C. Frost, M. Allmark, C. Johnstone, T. ODoherty, Effects of wave-current interactions on the performance of tidal stream turbines, 3rd Asian Wave and Tidal Energy Conference, 2016.

[35] S. C. Tedds, I. Owen, R. J. Poole, Near-wake characteristics of a model horizontal axis tidal stream turbine, Renewable Energy 63 (2014) 222-235.

[36] R. E. Murray, S. Ordonez-Sanchez, K. E. Porter, D. A. Doman, M. J. Pegg, C. M. Johnstone, Towing tank testing of passively adaptive composite tidal turbine blades and comparison to design tool, Renewable Energy 116 (2018) 202214.

[37] J. I. Whelan, J. M. R. Graham, J. Peir, A free-surface and blockage correction for tidal turbines, Journal of Fluid Mechanics (2009) 281-291.

[38] J. Schluntz, R. Willden, The effect of blockage on tidal turbine rotor design and performance, Vol. 81, 2015, pp. 432 - 441. doi:https: //doi.org/10.1016/j.renene.2015.02.050.

URL http://www.sciencedirect.com/science/ article/pii/S0960148115001664

[39] S. Ordonez-Sanchez, K. Porter, R. Ellis, C. Frost, M. Allmark, T. Nevalainen, T. ODoherty, C. Johnstone, Numerical modelling techniques to predict rotor imbalance problems in tidal stream turbines, 12th European Wave and Tidal Energy Conference, 2017. 
[40] H. Dumitrescu, V. Cardos, The influence of surface gravity waves on marine current turbine performance, Wind Turbine Aerodynamic Performance (1998) 141149.

[41] L. Eliassen, Aerodynamic loads on a wind turbine (2015).

[42] T. Blackmore, L. E. Myers, A. S. Bahaj, Effects of turbulence on tidal turbines: Implications to performance, blade loads, and condition monitoring, International Journal of Marine Energy (2016) 1-26.

[43] K. Porter, S. Ordonez-Sanchez, M. Allmark, R. Ellis, C. Lloyd, T. ODoherty, C. Johnstone, Laboratory study of tidal turbine performance in irregular waves, in: 4th Asian Wave and Tidal Energy Conference., 2018.

[44] A. Mason-Jones, D. O'Doherty, C. Morris, T. O'Doherty, Influence of a velocity profile \& support structure on tidal stream turbine performance, Renewable Energy 52 (2013) 23 - 30. doi:https: //doi.org/10.1016/j.renene.2012.10.022.

URL http://www.sciencedirect.com/science/ article/pii/S0960148112006672

\section{Appendix A. Blade loading time series}




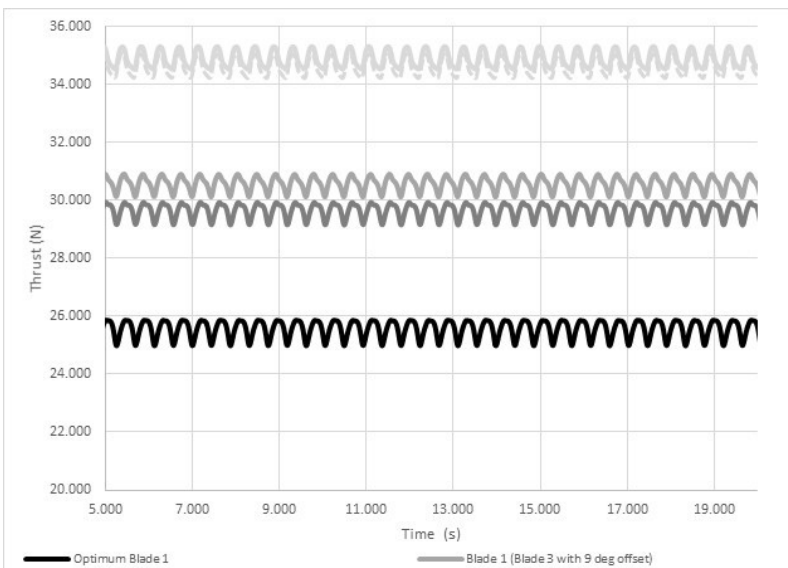

Bladimum Blade 1 (Blade 3 with 12 deg off set)

- Blade 1 (Blade 3 with 9 des offset)

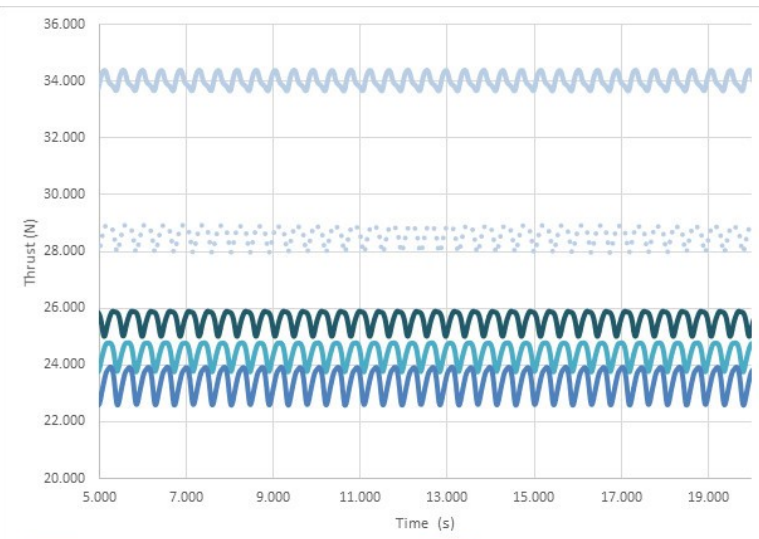

Optimum Blade 2 Blade 2 (Blade 3 with 12 deg off set)

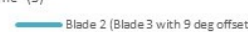

政 9 deg offse

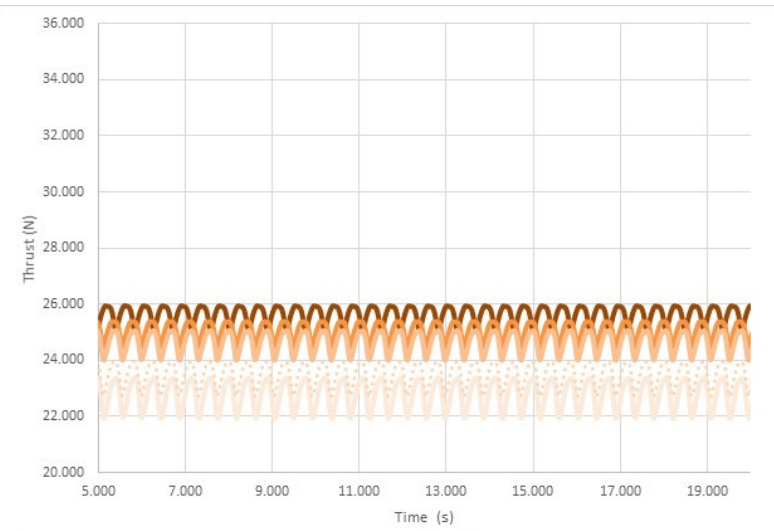

um Blade 3

Blade 3 with 9 deg offset

- Blade 3 with 12 deg offset

Blade 3 with 12 deg offset (Blade 2 with 9 deg offset)

Blade 3 with 9 deg offset (Blade 2 with 12 deg offser

Figure A.1: Thrust loading per blade: Blade 1 (top), Blade 2 (middle), Blade 3 (bottom). 

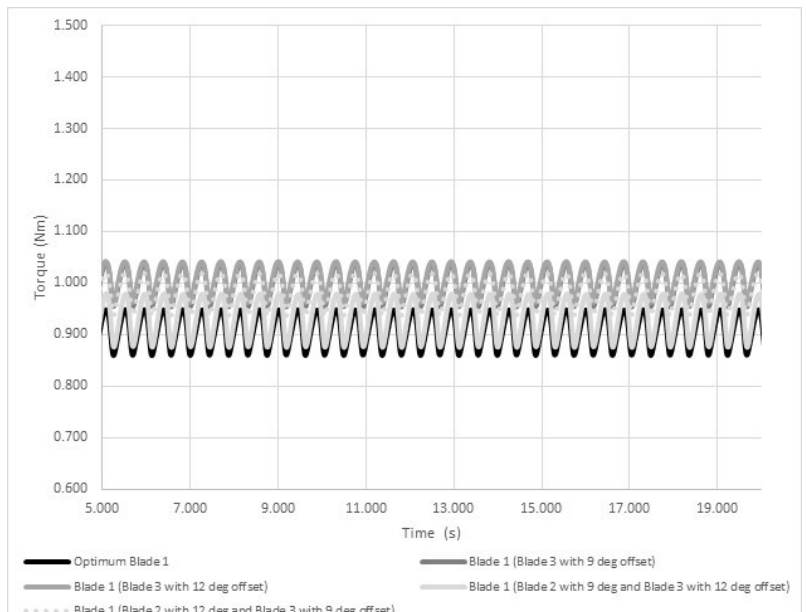

- Blade 1 (Blade 2 with 12 deg and Blade 3 with 9 des off set)

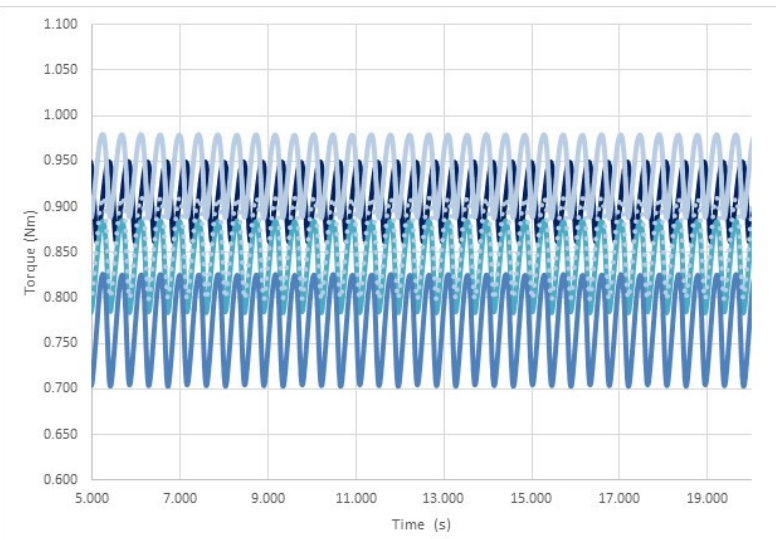

- Optimum Blade 2 (Blade 3 with 12 deg of set)

- Blade 2 with 12 deg offset (Ilade 3 with 9 deg offset)

Blade 2 with 9 deg offset (Blade 3 with 12 deg offset)

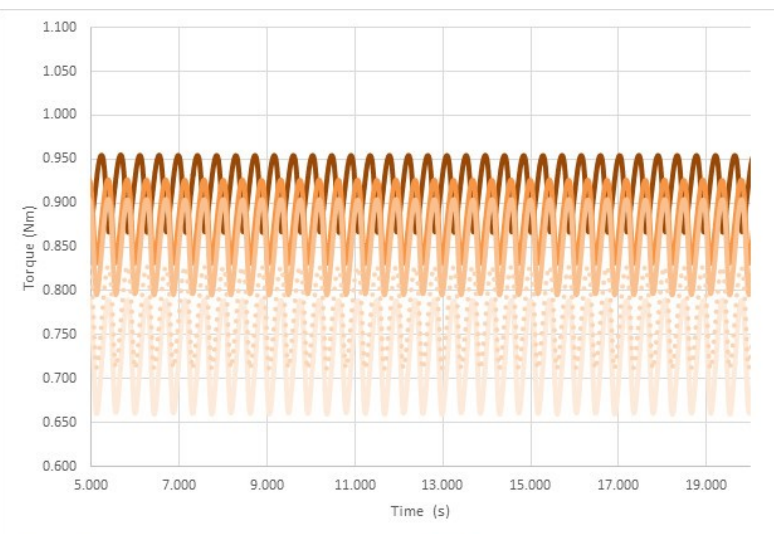

- Optimum Blade 3

Blade 3 with 12 deg offset

Blade 3 with 9 deg offset

Blade 3 with 9 deg offset (Blade 2 with 12 deg offset)

Figure A.2: Torque loading per blade: Blade 1 (top), Blade 2 (middle), Blade 3 (bottom). 